\title{
Spatial Distribution and Human Health Risk Assessment of Mercury in street dust resulting from various land use in Ahvaz, Iran.
}

\author{
Ahad Nazarpour ${ }^{1 凶}$, Navid Ghanavati ${ }^{2}$, Michael J. Watts ${ }^{3}$ \\ 1- Department of Geology, Faculty of Science, Azad University, Ahvaz Branch, Ahvaz, Iran \\ 2- Department of Soil Science, Faculty of Agricultural Science, Azad University, Ahvaz Branch, Ahvaz, Iran \\ 3- Inorganic Geochemistry, Centre for Environmental Geochemistry, British Geological Survey Keyworth UK
}

\begin{abstract}
Mercury as a toxic element and its associated health hazard has been an important topic of research for urban pollution for many years. In this paper, the spatial distribution, pollution assessment, and health risk associated with $\mathrm{Hg}$ in roadside dust 96 street dust samples, representing differing land uses have been investigated. Land uses included residential areas (RA), industrial areas (IA), public gardens (PG), roadside areas (RS) and suburban areas (SA) in the city of Ahvaz, Iran were investigated. Compared with other cities, the concentration of $\mathrm{Hg}$ in Ahvaz was considerably higher with a mean value of $2.53 \mathrm{mg} \cdot \mathrm{kg}^{-1}$, ranging from 0.02 to $8.75 \mathrm{mg} \cdot \mathrm{kg}^{-1}$. Residential areas exhibited higher Hg in street dust than other areas, as demonstrated by spatial mapping illustrating hot-spots associated with old urban areas with high residential density, high volume traffic of roadside areas, and industrial districts: including oil-drilling activities, steel smelting related industries, and small industrial towns around Ahvaz. However, $\mathrm{Hg}$ concentrations in street dust near to the public gardens (PG) and suburban areas (SA) were not at elevated levels compared other land uses investigated in this study. A health risk assessment model of non-carcinogenic effects was evaluated for both children and adults. The HQ values also revealed that the main exposures route for children and adults decreased as follows: vapour $>$ ingestion $>$ dermal contact $>$ inhalation. The Hazard Index (HI) in each area is less than the safe level $(\mathrm{HI} \leq 1)$ for children and adults, but higher for children. The HI value decrease as the following order: $\mathrm{RS}>\mathrm{IA}>\mathrm{RA}>\mathrm{SA}>\mathrm{PG}$, which indicates potentially serious health hazards for children in the study areas.
\end{abstract}

Key words: Mercury, Health assessment, Street dust, Ahvaz, Iran

\section{Introduction}

Mercury $(\mathrm{Hg})$ as an ever-present potential toxic metal is a considerable potential hazard to the environment and on human health (Sun et al. 2013; Farzin et al. 2008; Fu et al. 2012). Mercury in dust collected from the streets can easily enter the human body and bloodstream during inhalation, dermal contact, and ingestion (Wei et al. 2015). High levels of $\mathrm{Hg}$ cause adverse effects on brain, nervous system, gingivitis tremors, liver, and heart muscle (Farzin et al. 2008; Sun et al. 2013). The main origins of $\mathrm{Hg}$ in the environment are natural and anthropogenic sources (Chen et al. 2010; Solgi et al. 2014). Natural emission of $\mathrm{Hg}$ coming from volcanoes, weathering of rock and ores, soil evaporation, forest fires (Chen et al. 2010; Feng et al. 2003), whereas human activities such as municipal solid waste, pharmaceutical industry, mining, fuel combustion, electronic, paint and paper industries are the most important anthropogenic origins of $\mathrm{Hg}$ in the environment (Rodrigues et al. 2006; Biester et al. 2002; Chatterjee et al. 2014). Owing to the bioaccumulation, persistency, and toxicity of $\mathrm{Hg}$, it was itemised as a priority pollutant in the controlled environment by the United Nations Environment Programme (UNEP), World Health Organisation (WHO) and Food and Agriculture Organisation (FAO) (Chen et al. 2010; Xinmin et al. 2006). Mercury mostly remains in gaseous and particulate phases, unlike other toxic metals that tend to exit only as particulate phase (Solgi et al. 2014). The dust collected from the streets in this study are a combination of airborne particulate matter with a diameter less than $10 \mu \mathrm{m}$ and is frequently constituted of fuel combustion dust, and secondary dust derived from relocated urban soil particles (Hu et al. 2011; Xinmin et al. 2006; Ying et al. 2009). The dust collected from the streets provides evidence of anthropogenic activity, geological and geographical sources. Comparison of soils and dust in an urban environment show that collected dust from the streets are easily affected by urban populations, particularly children (Hu et al. 2011). Moreover, previous works confirm that toxic metal enrichment in street dust are mostly higher than soil (Li et al. 2001; Lu et al. 2010; Manta et al. 2002; Ordonez et al. 2003; Shi et al. 2008; Wei and Yang 2010; Xinmin et al. 2006). In general, the study of ecological risk and health risk assessment of toxic metals like $\mathrm{Hg}$, especially in street

๑ Corresponding Author. E-mail: A.nazarpour@iauahvaz.ac.ir, Phone: +989163721558, Fax: +986133348376 
dust may be more significant than urban soils. Therefore, there are limited related literature for developing countries, especially in Iran, which focused on the toxic metal content, spatial distribution, pollution assessment, and source identification (Dankoub et al. 2012; Farzin et al. 2008; Karimi et al. 2011; Solgi et al. 2014; Soltani et al. 2015). The US EPA's human health risk and ecological risk assessment methods has been effectively applied to investigate toxic metals from street dust for children and adults (US EPA, 1986, 2001, 2002; Hu et al. 2011; Wei and Yang 2010; Wei et al. 2015).

Ahvaz ( $31^{\circ} 19^{\prime} 45^{\prime \prime} \mathrm{N}$ and $\left.48^{\circ} 41^{\prime} 28^{\prime \prime}\right)$, the capital of Khuzestan province in Iran, with a population of approximately 1.32 million in 2016, is situated in south west Iran bordering Iraq, Kuwait and Saudi Arabia, whose deserts are the main source of dust events in the Middle East (Zarasvandi et al. 2011a and b). Ahvaz is one of the most important cities in Iran, owing to the presence of large industrials plants. For example, the National Iranian South Oil Company (NISOC), National Iranian Drilling Company (NIDC), Khuzestan Steel Company (KSC), Iran National Industrial Group (INIG) Khuzestan Oxin Steel Company (KOSC) and surrounding industrial towns has made Ahvaz as one of the most important industrial centres of Iran and it in turn, attracted many economic migrants to Ahvaz. In this study, the spatial distribution of $\mathrm{Hg}$, ecological risk and human health risk assessment of $\mathrm{Hg}$ in urban street dust was investigated across five parts of the Ahvaz city areas. These included; residential areas (RA), industrial areas (IA), public gardens (PG), and roadside areas (RS) and suburbs (SA). The study outcomes are valuable for environmental scheduling and development through identification of hotspots, which will help to inform mitigation strategies.

\section{Material and methods}

\subsection{Sampling and treatments}

In July 2014, ninety six (96) street dust samples were collected from the 2 city, with locations shown in Figure 1 . The number of samples for each of land uses were as follow: 23 samples for IA, 25 samples for RA, 25 samples for RS, 13 samples for SA, and 10 samples for PG. In addition, five dust samples were collected from new developed suburban area with no industrial activities high dense population and traffic volume as background samples (Fig. 1). Samples were selected using a commercial vacuum cleaner in the driest month of the year to prevent rain-washing away street dusts. A Geographical Information System (GIS) technique "create random points" were selected to create a sampling strategy that cover the whole of study area. Finally, the sampling points were classified according to the target land uses. The meteorological conditions were steady throughout the sampling, with no rainfall during one month earlier of sample collection. About $500 \mathrm{~g}$ of a composite street dust sample was collected by brushing an area of $1 \times 1 \mathrm{~m}^{2}$ from the pavements. The samples were sieved through a $220 \mathrm{mesh}(63 \mu \mathrm{m})$, air-dried and stored in polyethylene bags and labelled based on Tanner et al. (2008) and McKenzie et al. (2008).

Five grammes of dust collected from the street dust samples were mixed in highly purified nitric-hydrofluoric perchloric acids $\left(5 \mathrm{~mL} \mathrm{HNO}_{3}-4 \mathrm{~mL}\right.$ HCL- $\left.2 \mathrm{HClO}_{4}\right)($ Merck Ltd) to dissolve the street dust samples for measurement of $\mathrm{Hg}$, based on the protocol GB/T 17441-1997 and GB/T 17238-1997 (Griepink and Tölg 1989). The Hg concentration of street dust samples were determined by Atomic Absorption Spectrometry (AAS) (220Z, Varian Co., Australia). The Quality assurance (QA) and quality control (QC) was assessed by measurement of blank and duplicate samples and certified reference material NIST 2710 which provided an accuracy of $100 \pm 5 \%(\mathrm{n}=15)$, whilst the precision of duplicate samples was 4 to $6 \%$.

\subsection{Pollution Index (PI)}

To evaluate the extent of pollution, a modified pollution index (PI) for $\mathrm{Hg}$ was assigned to each sampling point (Huang 1987). The PI was expressed as:

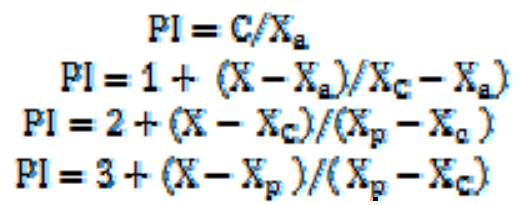

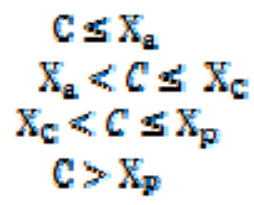


Where $\mathrm{C}$ is the measured value of $\mathrm{Hg}$ in the study area, $\mathrm{Xa}$ is the maximum limit value of the $\mathrm{Hg}, \mathrm{Xc}$ and $\mathrm{Xp}$ are the maximum limit value of the low and high level of pollution, respectively. The values of $X_{\mathrm{a}}, \mathrm{X}_{\mathrm{c}}$ and $\mathrm{X}_{\mathrm{p}}$, for $\mathrm{Hg}$ are $0.15,1$ and $1.5 \mathrm{mg} \cdot \mathrm{kg}^{-1}$ (Yu et al. 2004).

The PI value was categorised as: non-pollution for $\mathrm{PI}<1$, low level of pollution $(1<\mathrm{PI}<2)$ and high pollution level (PI>3) (Yu et al. 2004).

\subsection{Health risk assessment model}

The human health risk assessment is a useful method to obtain further evidences for the risk management of heavy metals in the metropolitan environment. Based on the developed US Environmental Protection Agency (US EPA 1986) and Exposure Factors Handbook (US EPA 1997), mercury (Hg) exposure from street dust can occur via four main paths in adults and children.

(1) Daily amount of exposure of direct hand to mouth ingestion of dust particles ( $\left.D_{\text {ing }}\right)$,

(2) Daily amount of exposure of mouth and nose inhalation of suspended particles ( $\left.D_{\text {inh }}\right)$

(3) Daily amount of exposure of dermal contact with dust particles ( $\left.D_{\text {dermal }}\right)$.

Mercury exposure through each of the four paths can be expressed and calculated using Eqs. (2- 5) (US EPA 1997, 2001 and 2002) and (Zheng et al., 2010a, b).

$$
\begin{gathered}
A D D_{\text {ing }}=\frac{C \times \operatorname{Ing} R \times C F \times E F \times E D}{B W \times A T} \\
A D D_{\text {inh }}=\frac{C \times \operatorname{Inh} R \times E F \times E D}{P E F \times B W \times A T} \\
A D D_{\text {dermal }}=\frac{C \times S A \times C F \times A F \times A B F \times E F \times E D}{B W \times A T} \\
A D D_{\text {Vapour }}=\frac{C \times \operatorname{InhR} \times E F \times E D}{V F \times B W \times A T}
\end{gathered}
$$

The exposure parameters that were employed to the health risk assessment models are summarised in Table 1 . The data are chosen by applying background values from US EPA (1997, 2001, and 2002). Then the daily contact dose for three pathways $\left(\mathrm{D}_{\text {ing, }}, \mathrm{D}_{\text {inh, }}\right.$, and $\left.\mathrm{D}_{\text {dermal }}\right)$, Hazard Quotient $(\mathrm{HQ})$, and Hazard Index $(\mathrm{HI})$ models were calculated Eqs. (6 and 7). HI denotes to the "total Hazard Quotient (HQ) of several materials or exposure paths" (US EPA, 1986). Therefore, a mixture of non-cancerous risk can be assessed by calculating the HI of every exposure pathway such as ingestion, dermal, and inhalation (US EPA, 1989). The possible non-carcinogenic and carcinogenic risks were computed by applying subsequent calculations (US EPA, 1989):

$$
\begin{aligned}
& H Q_{i}=\frac{A D D_{i}}{R_{f} D_{i}} \\
& H I=\sum H Q_{i}
\end{aligned}
$$

The reference dose $\left(\mathrm{R}_{\mathrm{f}} \mathrm{D}\right)\left(\mathrm{mg} \mathrm{kg}^{1}\right.$ day $\left.^{1}\right)$ is an estimate of high level acceptable hazards for humans during regular contact, and $i$ is the route of exposure. The threshold $\mathrm{R}_{\mathrm{f}} \mathrm{D}$ can be utilised to calculate whether there is a harmful impact throughout life. Reference dose for mercury used in this study were taken from the US Department pf Energy's RAIS 
compilation (2004), which are 3.0E-4 for direct ingestion, 2.10E-5, for dermal absorption and 8.57E-5 for inhalation through not only mouth and nose, but also vapor.

The ratio of average daily dose (ADD) and reference values can be utilised in determining the health effect of toxic metals. Values with lower than the reference dose indicate that there is no harmful health impact. On the other hand, the ADD value higher than the $\mathrm{R}_{\mathrm{f}} \mathrm{D}$, indicate that the contact pathway will cause harmful human health effects (US EPA, 1997).

Where:

$\mathrm{HQ} \leq 1$ : there are no harmful health effects

$\mathrm{HQ}>1$ : there are harmful health effects

The HI value is the total of the HQs and implies the total risk of non-carcinogenic for a single toxic metal.

If $\mathrm{HI}<1$ : indicate that there is no risk of non-carcinogenic impacts.

If $\mathrm{HI}>1$ : arise a probability of non-carcinogenic impacts with the increasing HI value (US EPA, 2001, 2002).

\section{Results and Discussion}

\subsection{Mercury concentrations}

Statistical analysis of $\mathrm{Hg}$ in the Ahvaz street dust samples including local background value are presented in Table 2. Mercury concentrations varied from 0.02 to $8.75 \mathrm{mg} . \mathrm{kg}^{-1}$ with an average value $2.53 \mathrm{mg} . \mathrm{kg}^{-1}$. Positive coefficient skewness (0.74) indicating that $\mathrm{Hg}$ concentration values do not have a normal distribution pattern (Fig. 2). In addition, Kolmogorov-Smirnov (K-S) normality test, indicate that Hg do not follow a normal distribution (K-S; P $>0.05$ ), which indicates the presence of samples containing high concentrations and hotspots of $\mathrm{Hg}$ in street dust. The mean value of $\mathrm{Hg}$ in Ahvaz street dust samples was 62 times greater than the background values (Table 2). These values imply that $\mathrm{Hg}$ in the street dust from Ahvaz were affected by anthropogenic sources.

A spatial distribution map of $\mathrm{Hg}$ overlapping with the location of the main anthropogenic pollution sources might indicate the possible source of $\mathrm{Hg}$ in street dust from Ahvaz. As indicated in Fig (3) the main hot spots were distributed in the old urban area with high residential density, traffic emission, and long-term deposit of Hg. Furthermore, areas, which coincided with industrial activities such as oil-drilling, steel smelting related industries, and small industrial towns, also exhibited a high level of pollution (Fig 3). Mercury concentrations in the street dust depends on some factors including residential density, industrial materials, traffic volume, and technologies employed, as well as local metrological situations and wind direction (Chen et al. 2010). According to different land used, the mean value of $\mathrm{Hg}$ concentration followed the sequence: $\mathrm{RS}>\mathrm{IA}>\mathrm{RA}>\mathrm{PG}>\mathrm{SA}$. This order indicate that roadside and industrial land uses as a result of more anthropogenic activities including traffic emission, steel smelting industry, oil-based mud drilling activity by NIDC in suburban area, Carbon Black company are the main sources of toxic metals in Ahvaz city, and have more potential of accumulation of toxic metals such as $\mathrm{Hg}$. The mean value of RS was greater than the other types of land-use as shown in (Table 2). It is obvious that fuel combustion is one of the main important $\mathrm{Hg}$ sources (Sun et al. 2013; Tian et al. 2010), which accounts for about $20 \%$ of the total anthropogenic $\mathrm{Hg}$ emission in the studied city (Statistic Bureau of Wuhan, 1990-2011).

$\mathrm{Hg}$ concentration in Ahvaz street dust is high in comparison to many other cities in the world (Fig .4). For example, whilst the mean concentration of $\mathrm{Hg}$ in the all samples in the study area is lower than Aviles, Spain (Lu et al. 2009), meanwhile, it was higher than that in Beijing, China (Xinmin et al. 2006); Shanghai, China (Shi et al. 2011), Baoji, China (Lu et al. 2009; Tang et al. 2013); Taipei, Taiwan (Zhang et al. 2014), Hong Kong (Tanner et al. 2008); Ottawa, Canada (Rasmussen et al. 2001); Kavala, Greece (Christoforidis and Stamatis, 2009); Luanda, Angola (Lu et al., 2009); and Shiraz, Iran (Keshavarzi et al. 2015) and higher than the UK environmental guideline value (1.0 mg. $\mathrm{kg}^{-1}$; DEFRA and Environmental Agency, 2009).

\subsection{Metal pollution index}

The pollution index of $\mathrm{Hg}$ was calculated based on Huang (1987), and it ranged from 0.26 to $16.33 \mathrm{mg} \mathrm{kg}^{-1}$, with the mean of $5.86 \mathrm{mg} \mathrm{kg}^{-1}$ (Table 3). Descriptive statistical analysis and number of samples in each class of PI for street dust across each land-use category are presented in Table 3. Assessment of street dust samples shows that there were 7 dust samples (7\%) with a PI $\leq 1,2$ street dust (2\%) had a PI between 1 and 2 . Thirteen street dust samples $(14 \%)$ had a PI between 2 and 3 and 74 dust samples (77\%) had a PI>3, exhibiting a high level of $\mathrm{Hg}$ pollution. 
The proportion of pollution levels of $\mathrm{Hg}$ in Ahvaz street dust samples are presented in Table 3. The mean concentration of $\mathrm{Hg}$ in each land-use decreases as follow: $\mathrm{RA}>\mathrm{RS}>\mathrm{PG}>\mathrm{IA}>\mathrm{SA}$. The concentration of $\mathrm{Hg}$ from the residential area (RA) (N=25) ranged from 0.93 to $13.83 \mathrm{mg} \mathrm{kg}^{-1}$, with a mean of $6.68 \mathrm{mg} \mathrm{kg}^{-1}$, was the highest category and higher than the mean $\mathrm{Hg}$ concentrations reported for cities shown in Table 3. In addition, as shown in Table 3, over 95\% of the street dust samples in RA, indicate $\mathrm{Hg}$ pollution in the study area. In general, more than $84 \%$ of RS street dust, $82 \%$ of IA samples, $80 \%$ of RA samples, and $70 \%$ of PG street dust samples were highly contaminated with $\mathrm{Hg}$. PI values in different land-use indicated serious anthropogenic activities, which resulted in the accumulation of $\mathrm{Hg}$ in street dust in Ahvaz.

Overall, these findings suggest that the street dust from Ahvaz city is polluted from anthropogenic Hg emissions. Dust samples with high and moderate $\mathrm{Hg}$ pollutions were located in areas with high dense pollution, high traffic volume, and manufacturing companies such as steel smelting, chemical industries, industrial towns, drilling pits, and uncontrolled oil-based mud.

\subsection{Health risk assessment of mercury}

The possibility of adverse effects and health risk of $\mathrm{Hg}$ in urban street dust was assessed. The results of the health risk assessment are presented in Table 4, and indicated that the average daily dose (ADD) and HQ values for Hg in street dust particles for adults and children are similar and decreases in the following order for adults and children: $\mathrm{ADD}_{\text {Vapour }}>\mathrm{ADD}_{\text {ing }}>\mathrm{ADD}$ dermal $>\mathrm{ADD}$ inhalation. For adults and children, the path of vapour was higher compared to ingestion absorption dermal contact and inhalation exposure of re-suspended dust. The results also showed that for non-carcinogenic impacts, vapour seemed to be the major path of contact to dust collected from the street particles, therefore causing a higher health risk to adult and children for $\mathrm{Hg}$, followed by ingestion, dermal contact, and inhalation absorption. HQ values for adults exhibited low variation across each land-use and the order of direct vapour $>$ ingestion $>$ dermal $>$ inhalation contact are the major paths of contact for adults and children in each landuse area. The total HQ of studied vapour in studied land uses account for more than $80 \%$ of the HI value. In the case of children, inhalation of mercury vapour is the major path of exposure in all of the exposure pathways, which was compatible with Fang et al. (2011) and Sun et al. (2013).

It can be observed that children are more likely to be exposed through hand-to-mouth transfer. However, daily outside activities of adults such as rubbing sweat, consumption of food outside, or not washing hands or faces before eating or drinking, may also cause the risk of ingestion and dermal exposure of $\mathrm{Hg}$ in re-suspended street dust on food, hands or faces. The inhalation and vapour of $\mathrm{Hg}$ from re-suspended particles through mouth and nose is likely to be negligible once associated with other pathways (Zheng et al. 2010a). Similar outcomes were found in earlier reports of exposure to toxic metals in metropolitan street dust (Ferreira-Baptista and De Miguel 2005; Zheng et al. 2010a). It is apparent that the increase of contact rate and inhalation and subsequently vapour exposure can result in the non-carcinogenic harmful special impacts to the tissues of children. Exposure to street dust in large amounts/dose by children may also cause non-carcinogenic results, as reported for other investigations (Ferreira-Baptista and De Miguel 2005; Sun et al. 2013; Zhang et al. 2014).

Analyses indicated that the $\mathrm{HI}$ value for $\mathrm{Hg}$ in each sample type for children and adults, showed that daily vapour inhalation and ingestion of street dust were 0.55 and 0.21 , therefore, lower than the safe level $(=1)$. The HI values for discrete land uses for children and adults is represented in Table 4. Compared to adults, the non-carcinogenic health risk of children due to greater sensitivity to $\mathrm{Hg}$ exposure is higher. The $\mathrm{HI}$ for each land-use were lower than the safe level $(\mathrm{HI} \leq 1)$ in both of children and adults, which decreases as the following order: $\mathrm{RS}>\mathrm{IA}>\mathrm{RA}>\mathrm{SA}>\mathrm{PG}$, indicating that exposure of $\mathrm{Hg}$ in street dust would result in potentially adverse health impacts for children in each study area. The HI values also show that the highest level of risk is related to samples, which are close to roadside (RS) and industrial area (IA) land uses (Table 4). These results confirm that high traffic volume, and industrial activities are the main sources of $\mathrm{Hg}$ in Ahvaz street dust. On the other hand, the lowest HI are related to public garden (PG) samples which is lower than the safe level $(\leq 1)$ in children and adults. With regarding, the high HI value for road side land use, vapour pathway is the main route of $\mathrm{Hg}$ in Ahvaz street dust samples, as evidenced by suspended particles from traffic emission. There were no non-carcinogenic risk of $\mathrm{Hg}$ in public gardens (PG) for adults and children. Non-carcinogenic risks for children from $\mathrm{Hg}$ indicated more potential harmful health risks, approximately 4-6 times greater than adults in the Ahvaz. 
Meza-Figueroa et al. (2007) reported that HI values were greater than the safe level (HI>1) in all studied samples for children with more hand-to-mouth action for what is a more subtle sub-population, by which dust containing $\mathrm{Hg}$ and other toxic metals can be freely inhaled. The lower body mass of children results in relatively greater absorption and accumulation of $\mathrm{Hg}(\mathrm{mg} / \mathrm{kg}$-bodyweight/day) compared to adults (Wang et al. 2011). Consequently, the hazard health risk (HI) for children exposed to $\mathrm{Hg}$ in street dust is higher than that of adults. Vapour exposure is main pathway with higher risk for adults. This result was comparable to reported urban surface dust for Guangzhou, China (Wang et al., 2011), and can be described by the greater values of dermal exposure area (SA) and exposure duration (ED) of adults. Hence, the environmental and health risk effects of the enhanced $\mathrm{Hg}$ in the Ahvaz demand more detailed examination.

\section{Conclusion}

The $\mathrm{Hg}$ concentration in Ahvaz urban street dust ranged from 0.02 to $8.75 \mathrm{mg} \cdot \mathrm{kg}^{-1}$. Raw data for street dust was positively skewed and did not follow a lognormal distribution. The $\mathrm{Hg}$ content for street dust in each land-use decreased as $\mathrm{RS}>\mathrm{IA}>\mathrm{RA}>\mathrm{PG}>\mathrm{SA}$. The main reason for the high concentration of $\mathrm{Hg}$ in $\mathrm{RS}$ and IA was related to high traffic volume, fuel combustion, and industrial activities. The result of mapping the distribution of $\mathrm{Hg}$ in Ahvaz street dust suggests that the high concentration of $\mathrm{Hg}$ mainly coincides with source points, such as industrial districts and the high-density residential area with an old urban history. The $\mathrm{Hg}$ content also indicates a decreased trend from the center to suburban areas of city.

The health risk assessment model was employed for calculation and results showed potentially high non-carcinogenic harmful impacts of $\mathrm{Hg}$ on children and adults. The HQ values for the major exposure pathway for children and adults decrease as follows: vapour>ingestion $>$ dermal contact $>$ inhalation. For two populations, children showed higher health risk than adults, with the HI value for total samples were 0.55 for children, and 0.21 for adults. The HI for each land-use were lower than the safe level $(\mathrm{HI} \leq 1)$ for children and adults and decrease in a similar order as: $\mathrm{RS}>\mathrm{IA}>\mathrm{RA}>\mathrm{SA}>\mathrm{PG}$, indicating that exposure to $\mathrm{Hg}$ in street dust could have health consequences for children in the study areas.

\section{References}

Biester, H., Müller, G., and Schöler, H. (2002). Estimating distribution and retention of mercury in three different soils contaminated by emissions from chlor-alkali plants: part I. Science of the total environment 284: 177189.

Chatterjee, M., Sklenars, L., Chenery, S.R., Watts, M.J., Marriott, A, Rakshit, D., Santosh, S.K. (2014). Assessment of Total Mercury $(\mathrm{HgT})$ in sediments and biota of the Indian Sundarban wetland and adjacent coastal regions, Environment and Natural Resources Research, 4, 50-64.

Chen, X., Xia, X., Wu, S., Wang, F., and Guo, X. (2010). Mercury in urban soils with various types of land use in Beijing, China. Environmental Pollution 158: 48-54.

Christoforidis, A., and Stamatis, N. (2009). Heavy metal contamination in street dust and roadside soil along the major national road in Kavala's region, Greece. Geoderma 151: 257-263.

Dankoub, Z., Ayoubi, S., Khademi, H., and Sheng-Gao, L. (2012). Spatial distribution of magnetic properties and selected heavy metals in calcareous soils as affected by land use in the Isfahan region, Central Iran. Pedosphere 22, 33-47.

DEFRA (Department for Environment, Food and Rural Affairs) and Environment Agency. (2009). Soil Guideline Values for Mercury in Soil. Almondsbury, Bristol.

Fang, F.M., Wang, H.D., Lin, Y.S. (2011). Spatial distribution, bioavailability, and health risk assessment of soil Hg in Wuhu urban area, China. Environmental Monitoring and Assessment 179, 255-265.

Farzin, L., Amiri, M., Shams, H., Faghih, M. A. A., and Moassesi, M. E. (2008). Blood levels of lead, cadmium, and mercury in residents of Tehran. Biological trace element research 123, 14-26.

Feng, X., Tang, S., Shang, L., Yan, H., Sommar, J., and Lindqvist, O. (2003) Total gaseous mercury in the atmosphere of Guiyang, PR China. Science of the total environment 304, 61-72.

Ferreira-Baptista, L., and De Miguel, E. (2005). Geochemistry and risk assessment of street dust in Luanda, Angola: a tropical urban environment. Atmospheric Environment 39, 4501-4512.

Fu, X., Feng, X., Sommar, J., and Wang, S. (2012) A review of studies on atmospheric mercury in China. Science of the Total Environment 421, 73-81.

Griepink, B., \& Tölg, G. (1989). Sample digestion for the determination of elemental traces in matrices of environmental concern. Pure and Applied Chemistry, 61(6), 1139-1146.

Hakanson, L. (1980). An ecological risk index for aquatic pollution control. A sedimentological approach. Water research, 14(8), 975-1001. 
Hu, X., Zhang, Y., Luo, J., Wang, T., Lian, H., and Ding, Z. (2011). Bioaccessibility and health risk of arsenic, mercury and other metals in urban street dusts from a mega-city, Nanjing, China. Environmental Pollution 159, 12151221.

Huang, R. (1987). Environmental pedology. Higher Education, Beijing.

Karimi, R., Ayoubi, S., Jalalian, A., Sheikh-Hosseini, A. R., and Afyuni, M. (2011). Relationships between magnetic susceptibility and heavy metals in urban topsoils in the arid region of Isfahan, central Iran. Journal of Applied Geophysics 74, 1-7.

Keshavarzi, B., Tazarvi, Z., Rajabzadeh, M. A., and Najmeddin, A. (2015). Chemical speciation, human health risk assessment and pollution level of selected heavy metals in urban street dust of Shiraz, Iran. Atmospheric Environment 119, 1-10.

Li, X., Poon, C.-s., and Liu, P. S. (2001). Heavy metal contamination of urban soils and street dusts in Hong Kong. Applied geochemistry 16, 1361-1368.

Lu, X., Li, L. Y., Wang, L., Lei, K., Huang, J., and Zhai, Y. (2009). Contamination assessment of mercury and arsenic in roadway dust from Baoji, China. Atmospheric Environment 43, 2489-2496.

Lu, X., Wang, L., Li, L. Y., Lei, K., Huang, L., and Kang, D. (2010). Multivariate statistical analysis of heavy metals in street dust of Baoji, NW China. Journal of hazardous materials 173, 744-749.

Manta, D. S., Angelone, M., Bellanca, A., Neri, R., and Sprovieri, M. (2002). Heavy metals in urban soils: a case study from the city of Palermo (Sicily), Italy. Science of the Total Environment 300, 229-243.

McKenzie, E. R., Wong, C. M., Green, P. G., Kayhanian, M., and Young, T. M. (2008). Size dependent elemental composition of road-associated particles. Science of the Total Environment 398, 145-153.

Meza-Figueroa, D., De la O-Villanueva, M., and De la Parra, M. L. (2007). Heavy metal distribution in dust from elementary schools in Hermosillo, Sonora, México. Atmospheric Environment 41, 276-288.

Ordonez, A., Loredo, J., De Miguel, E., and Charlesworth, S. (2003). Distribution of heavy metals in the street dusts and soils of an industrial city in Northern Spain. Archives of Environmental Contamination and Toxicology 44, 0160-0170.

Rasmussen, P., Subramanian, K., and Jessiman, B. (2001). A multi-element profile of house dust in relation to exterior dust and soils in the city of Ottawa, Canada. Science of the Total Environment 267, 125-140.

Rodrigues, S., Pereira, M. E., Sarabando, L., Lopes, L., Cachada, A., and Duarte, A. (2006). Spatial distribution of total $\mathrm{Hg}$ in urban soils from an Atlantic coastal city (Aveiro, Portugal). Science of the total environment $\mathbf{3 6 8}$, 40-46.

Shi, G., Chen, Z., Bi, C., Wang, L., Teng, J., Li, Y., and Xu, S. (2011). A comparative study of health risk of potentially toxic metals in urban and suburban road dust in the most populated city of China. Atmospheric Environment 45, 764-771.

Shi, G., Chen, Z., Xu, S., Zhang, J., Wang, L., Bi, C., and Teng, J. (2008). Potentially toxic metal contamination of urban soils and roadside dust in Shanghai, China. Environmental Pollution 156, 251-260.

Solgi, E., Esmaili-Sari, A., and Riyahi-Bakhtiari, A. (2014). Spatial distribution of mercury in the surface soils of the urban areas, Arak, Iran. Bulletin of environmental contamination and toxicology 93, 710-715.

Soltani, N., Keshavarzi, B., Moore, F., Tavakol, T., Lahijanzadeh, A. R., Jaafarzadeh, N., and Kermani, M. (2015). Ecological and human health hazards of heavy metals and polycyclic aromatic hydrocarbons (PAHs) in road dust of Isfahan metropolis, Iran. Science of the Total Environment 505, 712-723.

Statistic Bureau of Wuhan. (1990-2011). Wuhan Statistics Yearbook. Wuhan Press (in Chinese).

Sun, G., Li, Z., Bi, X., Chen, Y., Lu, S., and Yuan, X. (2013). Distribution, sources and health risk assessment of mercury in kindergarten dust. Atmospheric Environment 73, 169-176.

Tang, R., Ma, K., Zhang, Y., and Mao, Q. (2013). The spatial characteristics and pollution levels of metals in urban street dust of Beijing, China. Applied geochemistry 35, 88-98.

Tian, H. Z., Wang, Y., Xue, Z. G., Cheng, K., Qu, Y. P., Chai, F. H., \& Hao, J. M. (2010). Trend and characteristics of atmospheric emissions of $\mathrm{Hg}$, As, and Se from coal combustion in China, 1980-2007. Atmospheric Chemistry and Physics, 10, 11905-11919.

Tanner, P. A., Ma, H.-L., and Yu, P. K. (2008). Fingerprinting metals in urban street dust of Beijing, Shanghai, and Hong Kong. Environmental science \& technology 42, 7111-7117.

US Department of Energy. (2004). RAIS: Risk Assessment Information System.

US EPA. (1997). Exposure factors handbook. EPA/600/P-95/002F. Washington, DC, EPA, Office of Research and Development.

US EPA. (1986). "Superfund Public Health Evaluation Manual. EPA/540/1-86.."

US EPA. (2001) "Child-Specific Exposure Factors Handbook. EPA-600-P-00-002B," National Center for Environmental Assessment. 
US EPA. ( 2002). "Child-Specific Exposure Factors Handbook. EPA-600-P-00-002B," National Center for Environmental Assessment.

Wang, W., Huang, M.-j., Kang, Y., Wang, H.-s., Leung, A. O., Cheung, K. C., and Wong, M. H. (2011). Polycyclic aromatic hydrocarbons (PAHs) in urban surface dust of Guangzhou, China: status, sources and human health risk assessment. Science of the total environment 409, 4519-4527.

Wei, B., and Yang, L. (2010). A review of heavy metal contaminations in urban soils, urban road dusts and agricultural soils from China. Microchemical Journal 94, 99-107.

Wei, X., Gao, B., Wang, P., Zhou, H., and Lu, J. (2015). Pollution characteristics and health risk assessment of heavy metals in street dusts from different functional areas in Beijing, China. Ecotoxicology and environmental safety 112, 186-192.

Xinmin, Z., Kunli, L., Xinzhang, S., Jian'an, T., and Yilun, L. (2006). Mercury in the topsoil and dust of Beijing City. Science of the Total Environment 368, 713-722.

Ying, L., Dongxing, Y., Min, L., Zhenbin, G., Xiyao, L., and Zhen, Z. (2009). Distribution characteristics of total mercury and methylmercury in the topsoil and dust of Xiamen, China. Journal of Environmental Sciences 21, 1400-1408.

Yu, L., Zhang, B., \& Zhang, S. Q. (2004). Heavy metal elements pollution evaluation on the ecological environment of the Sanjiang Plain based on GIS. Chinese Journal of Soil Science, 35(5), 529-532.

Zarasvandi, A., Moore, F., \& Nazarpour, A. (2011a). Mineralogy and morphology of dust storms particles in Khuzestan Province: XRD and SEM analysis concerning. Iranian Journal of Crystallography and Mineralogy, 19(3), 511-518.

Zarasvandi, A., Moore, F. and Nazarpour, A., (2011bFF). First Report On Pb Isotope Composition Of Dust Storms Particles In Khuzestan Province: Concerning On Source And Geo-Environmental Characteristics. Iranian Journal of Crystallography and Mineralogy, 19(2), 263-270

Zhang, D., Pan, X., and Lee, D.-J. (2014). Potentially harmful metals and metalloids in the urban street dusts of Taipei City. Journal of the Taiwan Institute of Chemical Engineers 45, 1727-1732.

Zheng, N., Liu, J., Wang, Q., and Liang, Z. (2010a). Health risk assessment of heavy metal exposure to street dust in the zinc smelting district, Northeast of China. Science of the Total Environment 408, 726-733.

Zheng, N., Liu, J., Wang, Q., and Liang, Z. (2010b). Heavy metals exposure of children from stairway and sidewalk dust in the smelting district, northeast of China. Atmospheric Environment 44, 3239-3245. 


\section{Figure Caption}

Fig.1. Location of samples sites in Ahvaz city and the main industrial centers.

Fig 2. Histograms of Hg concentration (a) and the log-transformed Hg (b).

Fig 3. Spatial distribution of $\mathrm{Hg}$ in urban street dust of Ahvaz (mg. $\mathrm{kg}^{-1}$ ).

Fig 4. Comparison of $\mathrm{Hg}$ concentration in urban soils in different cities. 


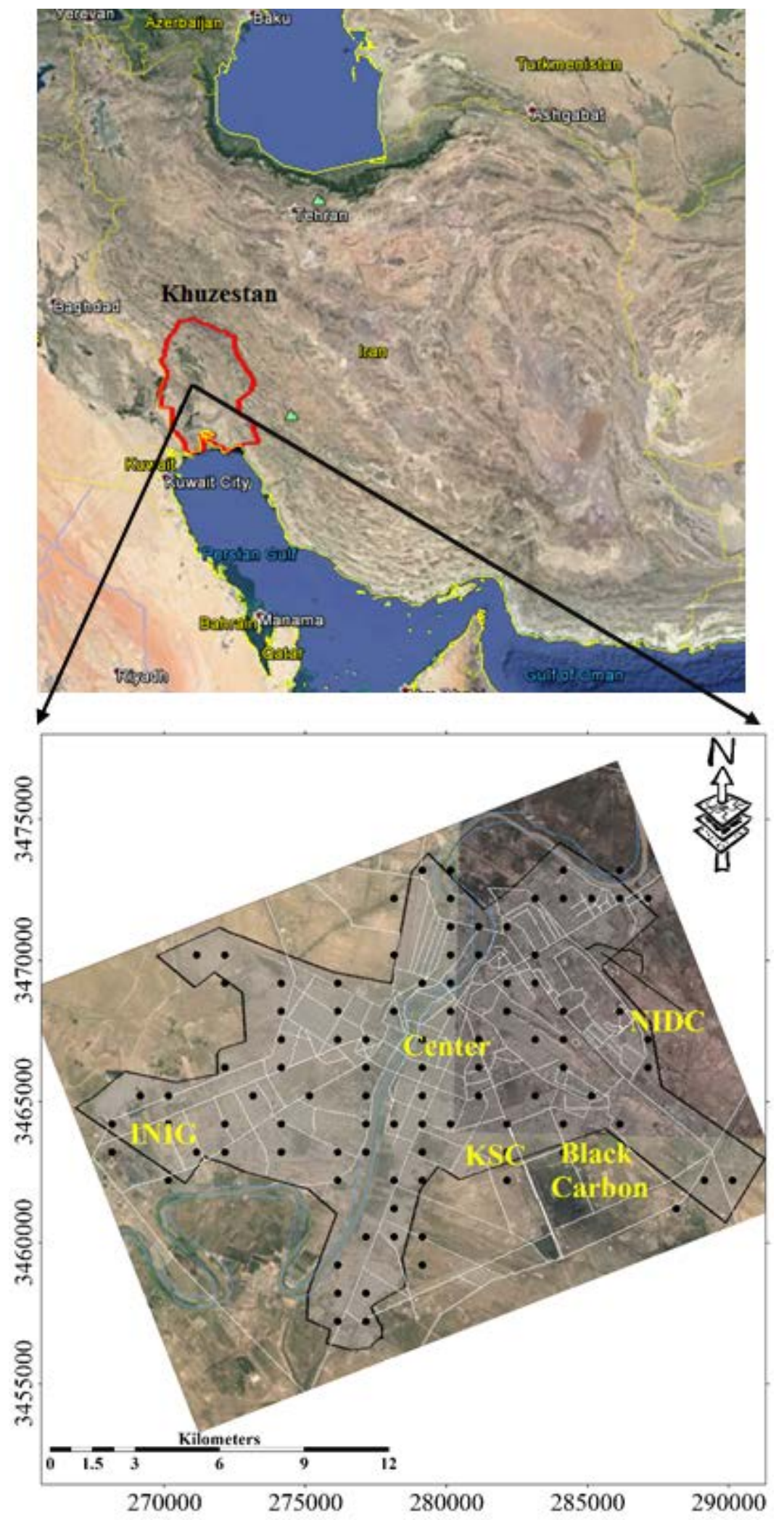

Fig. 1 

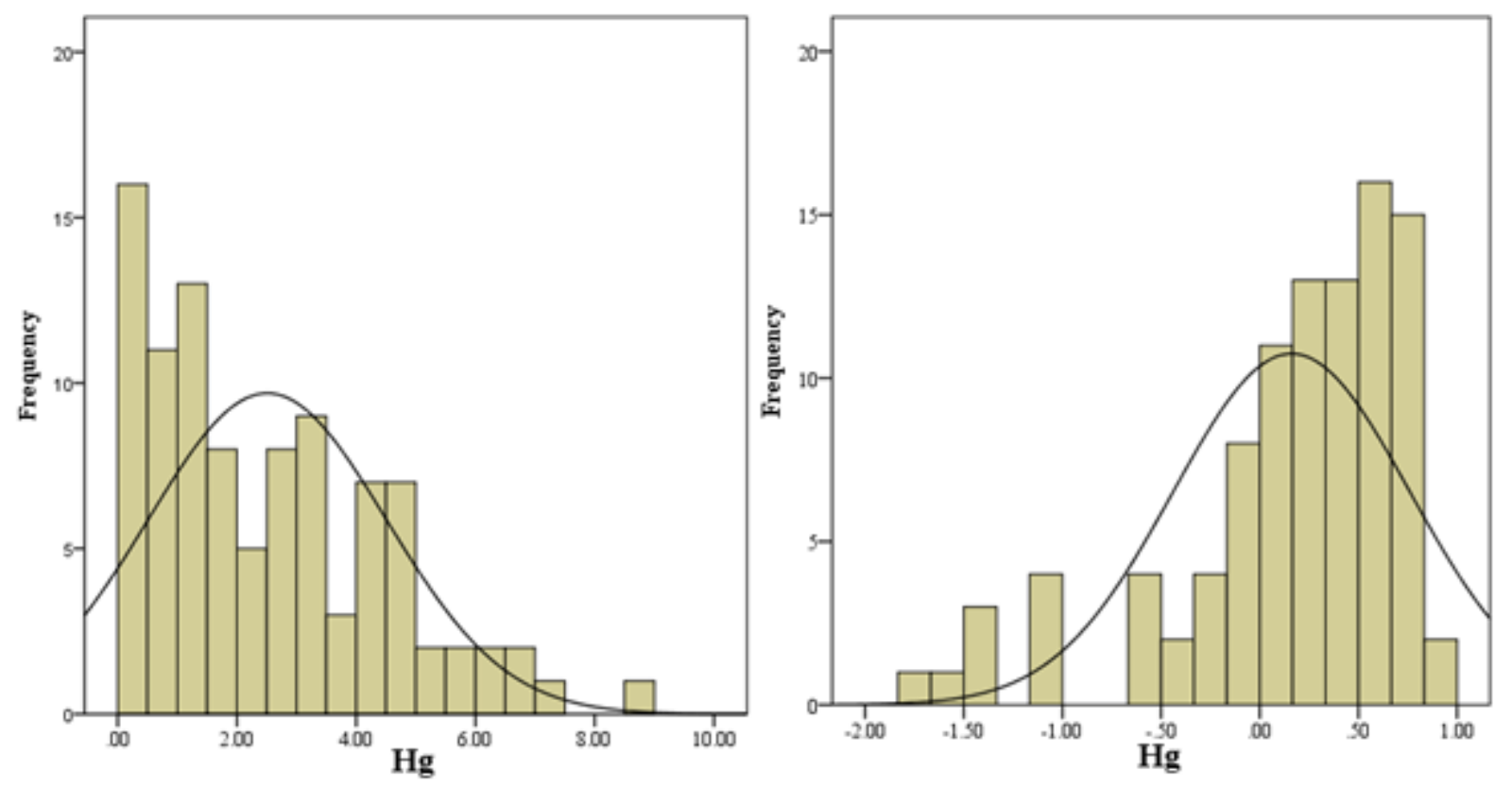

Fig. 2 


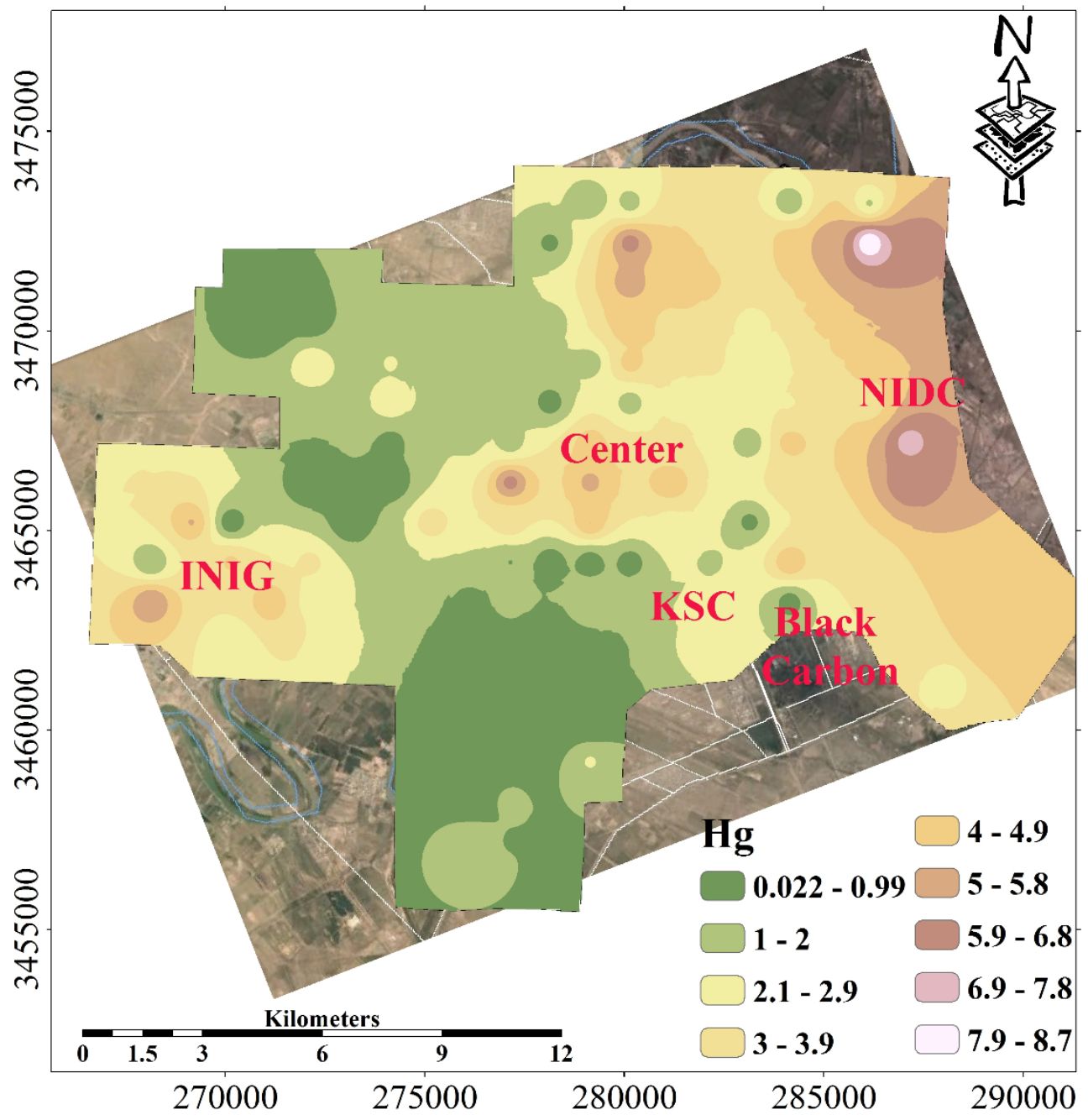

Fig. 3 


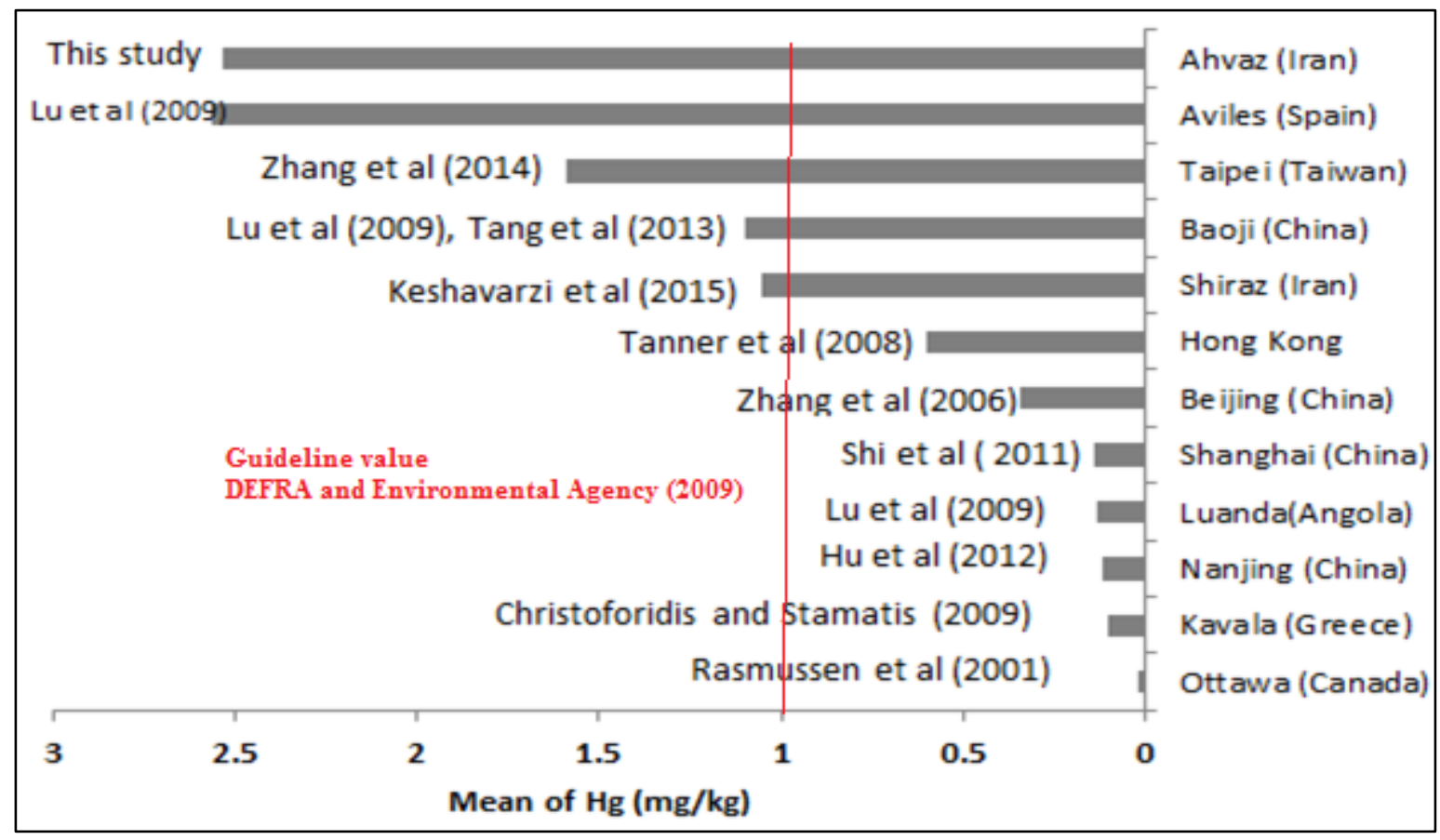

Fig. 4 


\section{Table Caption}

Table1. Exposure factor for metal doses.

Table 2. Mercury concentration from various land use in Ahvaz street dusts (mg/kg).

Table 3. Statistical results of pollution index (PI) of mercury in Ahvaz street dusts

Table 4. Health risk from mercury in street dusts of Ahvaz. 
Table1.

\begin{tabular}{|c|c|c|c|c|c|}
\hline Factor & Definition & Unit & $\begin{array}{c}\text { Value } \\
\text { Children }\end{array}$ & Adult & Reference \\
\hline $\mathrm{C}$ & $\begin{array}{l}\text { Mercury concentration in } \\
\text { dusts }\end{array}$ & $\mathrm{mg} / \mathrm{kg}$ & & & This study \\
\hline $\mathrm{R}_{\text {ing }}$ & ingestion rate of soil & mg/day & 100 & 200 & US EPA (2001a, 2001b) \\
\hline $\mathrm{EF}$ & exposure frequency & days/year & 350 & 350 & $\begin{array}{l}\text { Environmental site } \\
\text { assessment guideline (2009) }\end{array}$ \\
\hline ED & exposure duration & years & 6 & 24 & US EPA (2001a, 2001b) \\
\hline BW & average body weight & $\mathrm{kg}$ & 15 & 55.9 & $\begin{array}{l}\text { Environmental site } \\
\text { assessment guideline (2009) }\end{array}$ \\
\hline AT & average time & days & $365 \times \mathrm{ED}$ & $365 \times \mathrm{ED}$ & US EPA (1989) \\
\hline $\mathrm{CF}$ & conversion factor & $\mathrm{kg} / \mathrm{mg}$ & $1 \times 10^{-6}$ & $1 \times 10^{-6}$ & Li et al. (2011) \\
\hline $\mathrm{R}_{\text {inh }}$ & inhalation rate & $\mathrm{m}^{3} / \mathrm{kg}$ & 7.63 & 12.8 & Li et al. (2011) \\
\hline PEF & particle emission factor & $\mathrm{m}^{3} / \mathrm{kg}$ & $1.36 \times 10^{9}$ & $1.36 \times 10^{9}$ & US EPA (2001a, 2001b) \\
\hline SA & $\begin{array}{l}\text { surface area of the skin } \\
\text { that contacts the dust }\end{array}$ & $\mathrm{cm}^{2}$ & 1600 & 4350 & $\begin{array}{l}\text { Environmental site } \\
\text { assessment guideline (2009) }\end{array}$ \\
\hline $\mathrm{AF}$ & skin adherence factor & $\mathrm{mg} / \mathrm{cm}^{2}$ & 0.2 & 0.7 & US EPA (2011) \\
\hline $\mathrm{ABF}$ & dermal absorption factor & - & 0.001 & 0.001 & $\begin{array}{l}\text { US Department of Energy } \\
(2000)\end{array}$ \\
\hline
\end{tabular}


Table 2.

\begin{tabular}{cccccccc}
\hline & \multicolumn{7}{c}{ Hg Concentration (mg/Kg) } \\
& Max & Min & Mean & Skewness & SD & CV \\
\hline Total & 8.75 & 0.02 & 2.53 & 0.74 & 1.97 & 78.13 \\
Industrial area (IA) & 6.75 & 0.02 & 2.72 & 0.70 & 1.80 & 80.93 \\
Residential area (RA) & 7.25 & 0.07 & 2.18 & 0.53 & 2.05 & 68.78 \\
Roadside Area (RS) & 8.75 & 0.04 & 2.98 & 1.14 & 2.13 & 79.40 \\
Suburb area (SA) & 4.88 & 0.04 & 1.93 & 0.38 & 1.60 & 83.33 \\
Public garden (PG) & 5.80 & 0.09 & 2.07 & 0.27 & 1.95 & 75.80 \\
Background value & 0.041 & & & & & \\
Of Ahvaz & & & & & & \\
\hline
\end{tabular}

* Kolmogorov - Smirnov (K-S) test. 
Table 3.

\begin{tabular}{ccccccccc}
\hline & \multicolumn{3}{c}{ PI } & \multicolumn{3}{c}{ Number of sample } \\
\cline { 2 - 8 } Metals & Min & Max & Mean & $\begin{array}{c}\text { Number of } \\
\text { sample }\end{array}$ & $\begin{array}{c}\text { Non- } \\
\text { pollution }\end{array}$ & Low & Middle & High \\
\hline $\begin{array}{c}\text { Total } \\
\text { Industrial } \\
\text { area (IA) }\end{array}$ & 0.26 & 16.33 & 5.86 & 96 & $7(7.29 \%)$ & $2(2.08 \%)$ & $13(13.54 \%)$ & $74(77.09 \%)$ \\
$\begin{array}{c}\text { Residential } \\
\text { area (RA) }\end{array}$ & 0.27 & 13.00 & 5.27 & 23 & $3(13.04 \%)$ & $0(0 \%)$ & $1(4.34 \%)$ & $19(82.62 \%)$ \\
$\begin{array}{c}\text { Roadside area } \\
\text { (RS) }\end{array}$ & 0.53 & 16.33 & 6.16 & 25 & $1(4 \%)$ & $0(0 \%)$ & $4(16 \%)$ & $20(80 \%)$ \\
$\begin{array}{c}\text { Suburban } \\
\text { area (SA) }\end{array}$ & 0.53 & 9.88 & 4.73 & 13 & $2(15.38 \%)$ & $1(7.69 \%)$ & $1(7.69 \%)$ & $9(69.24 \%)$ \\
$\begin{array}{c}\text { Public garden } \\
\text { (PG) }\end{array}$ & 1.13 & 11.42 & 5.95 & 10 & 0 & $1(10 \%)$ & $2(20 \%)$ & $7(70 \%)$ \\
\hline
\end{tabular}


Table 4.

\begin{tabular}{|c|c|c|c|c|c|c|c|c|c|c|c|c|c|c|c|}
\hline \multirow[t]{2}{*}{ Metals } & \multirow[t]{2}{*}{ C(mgkg_1) } & \multicolumn{2}{|c|}{ ADDing } & \multicolumn{2}{|c|}{ ADDderm } & \multicolumn{2}{|c|}{ ADDinh } & \multicolumn{2}{|c|}{ HQing } & \multicolumn{2}{|c|}{ HQderm } & \multicolumn{2}{|c|}{ HQinh } & \multicolumn{2}{|c|}{ HI } \\
\hline & & Children & Adults & Children & Adults & Children & Adults & Children & Adults & Children & Adults & Children & Adults & Children & Adults \\
\hline Total & 2.53 & $3.1 \mathrm{E}-03$ & 0.4.17E-04 & 4.97E-06 & 1.27E-05 & 8.72E-08 & $5.02 \mathrm{E}-13$ & 10.36 & 1.39 & 0.24 & 0.61 & $1.01 \mathrm{E}-03$ & 5.85E-09 & 10.60 & 1.99 \\
\hline $\begin{array}{c}\text { Industrial } \\
\text { area (IA) }\end{array}$ & 2.22 & 8.96E-04 & $1.20 \mathrm{E}-04$ & 1.43E-06 & 3.66E-06 & 2.51E-08 & $1.44 \mathrm{E}-13$ & 2.98 & 0.40 & 0.07 & 0.17 & 2.93E-11 & $1.68 \mathrm{E}-16$ & 3.06 & 0.58 \\
\hline $\begin{array}{c}\text { Residential } \\
\text { area (RA) }\end{array}$ & 2.98 & 6.63E-04 & 8.90E-05 & $1.06 \mathrm{E}-06$ & $2.70 \mathrm{E}-06$ & $1.85 \mathrm{E}-08$ & $1.07 \mathrm{E}-13$ & 2.21 & 0.29 & 0.05 & 0.13 & 2.17E-04 & $1.24 \mathrm{E}-09$ & 2.27 & 0.42 \\
\hline $\begin{array}{l}\text { Road side } \\
\text { area (RS) }\end{array}$ & 2.68 & $1.04 \mathrm{E}-03$ & $1.40 \mathrm{E}-04$ & $1.66 \mathrm{E}-06$ & 4.25E-06 & 2.91E-08 & $1.68 \mathrm{E}-13$ & 3.46 & 0.46 & 0.08 & 0.20 & $3.40 \mathrm{E}-04$ & $1.96 \mathrm{E}-09$ & 3.55 & 0.67 \\
\hline $\begin{array}{l}\text { Sub urban } \\
\text { Area (SA) }\end{array}$ & 1.93 & 4.22E-04 & 5.66E-05 & $6.75 \mathrm{E}-07$ & $1.72 \mathrm{E}-06$ & 1.18E-08 & $6.81 \mathrm{E}-14$ & 1.40 & 0.18 & 0.03 & 0.08 & $1.38 \mathrm{E}-04$ & 7.94E-10 & 1.44 & 0.27 \\
\hline $\begin{array}{c}\text { Public } \\
\text { garden (PG) }\end{array}$ & 2.57 & 8.73E-05 & 1.17E-05 & $1.39 \mathrm{E}-07$ & 3.57E-07 & 2.45E-09 & $1.41 \mathrm{E}-14$ & 0.29 & 0.04 & 0.01 & 0.02 & 2.86E-05 & $1.64 \mathrm{E}-10$ & 0.30 & 0.06 \\
\hline
\end{tabular}

